\title{
The Reaction Mechanism of Polyamide Synthesis by Phosphorylation
}

\author{
Naoya Ogata and Hozumi Tanaka \\ Department of Chemistry, Sophia University, \\ 7 Kioi-Cho, Chiyoda-Ku, Tokyo, Japan.
}

(Received November 5, 1973)

\begin{abstract}
The reaction mechanism of the polyamide synthesis by phosphorylation with triaryl phosphite and imidazole was investigated in terms of the amidation reaction of model compounds and the polycondensation of various nylon salts. Triphenyl phosphite formed a complex with imidazole which reacted easily either with amine or carboxylic acid to form acyloxy phosphite or phosphoramide complexes. The electrondonating substituent of phenol of aryl phosphites retarded the amidation and polycondensation reactions, and, among various tertiary amines, only imidazole had a cocatalytic effect. The low molecular weight of the resulting polyamide was ascribed to the many competitive reactions of the phosphite-imidazole complex between amine and carboxylic acid, which resulted in the molar balance loss of amine or carboxylic acid. The reaction mechanism for the polycondensation of nylon salt by phosphorylation was again discussed in this paper.
\end{abstract}

KEY WORDS Polyamide / Polycondensation / Phosphorylation / Nylon Salt / Aryl Phosphite / Imidazole /

It was previously reported ${ }^{1,2}$ that polyamides are easily prepared at room temperature from various nylon salts by means of a phosphorylation reaction in the presence of triphenyl phosphite and imidazole, and polyhydrazides are also obtained at room temperature from dicarboxylic acid and dihydrazide by this method. ${ }^{3}$

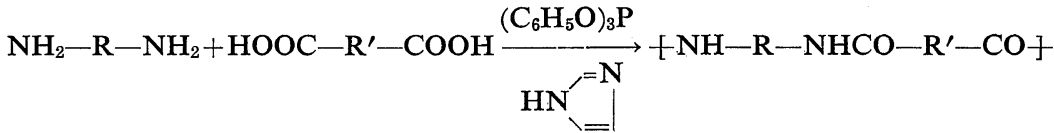

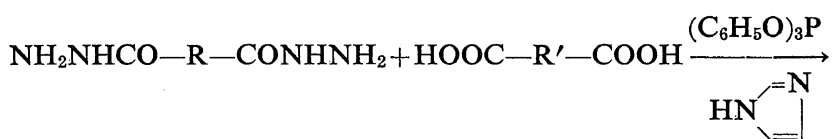

$$
\begin{aligned}
& +-\mathrm{NHNHCO}-\mathrm{R}-\mathrm{CONHNHCO}-\mathrm{R}^{\prime}-\mathrm{CO}+
\end{aligned}
$$

Yields of polyamide or polyhydrazide by this phosphorylation method were almost quantitative, while the molecular weights of the resulting polymers were not satisfactorily high. The polycondensation reaction proceeded in a heterogeneous phase and nylon salts or dihydrazides initially suspended in such solvents as dimethylformamide (DMF) were gradually transformed into a swollen polymer gel. However, the low molecular weight of the resulting polymers could not be attributed to the heterogeneity of the reaction phase since the copolycondensation reaction of two nylon salts proceeded in a homogeneous phase and the molecular weight of copolymers obtained was still not satisfactory. A termination reaction must therefore have occurred to stop the growth of polymer chains during the polycondensation by phosphorylation.

This paper aimed at the elucidation of the reaction mechanism of the polyamide synthesis by phosphorylation with aryl phosphite and imidazole so that a high-molecular-weight polymer could be obtained. 


\section{EXPERIMENTAL}

\section{Monomers and Reagents}

Various nylon salts were obtained by reacting diamines and dicarboxylic acids in methanol and purified by recrystallization. Commercially available imidazole and triphenyl phosphite were purified by recrystallization from benzene and vacuum distillation, respectively. Various triaryl phosphites were synthesized by reacting $\mathrm{PCl}_{3}$ with substituted phenols by a conventional method. ${ }^{4}$
Amidation Reaction by Phosphorylation

$n$-Butylamine or $n$-hexylamine were reacted with propionic acid in tetrahydrofuran (THF) with a monomer concentration of $0.5 \mathrm{~mol} / l$ at $30^{\circ} \mathrm{C}$ using the phosphorylation reaction with various triaryl phosphites and imidazole. The molar ratio of triaryl phosphite and imidazole to amine or carboxylic acid was adjusted to 3 to 1 . The reaction rate was determined by measuring the amount of $\mathrm{N}$-alkyl propionamide formed by means of gas chromatography using a polyethyleneglycol column.

$$
\begin{aligned}
& \mathrm{R}-\mathrm{NH}_{2}+\mathrm{C}_{2} \mathrm{H}_{5} \mathrm{COOH} \underset{\left.\mathrm{C}_{6} \mathrm{H}_{5} \mathrm{O}\right)_{3} \mathrm{P}}{\stackrel{(\underset{N}{\longrightarrow}}{\longrightarrow=}} \mathrm{N}-\mathrm{NHCO}-\mathrm{C}_{2} \mathrm{H}_{5} \\
& \mathrm{R} \text { : } n \text {-butyl or } n \text {-hexyl }
\end{aligned}
$$

Phenyl esterification of propionic acid was carried out in the presence of triphenyl phosphite and imidazole at various molar ratios and the rate of the ester formation was followed by gas chromatography.

$$
\mathrm{C}_{2} \mathrm{H}_{5} \mathrm{COOH}+\left(\mathrm{C}_{6} \mathrm{H}_{5} \mathrm{O}\right)_{3} \mathrm{P} \stackrel{\mathrm{HN}^{\prime=}=}{\stackrel{=}{\longrightarrow}} \mathrm{C}_{2} \mathrm{H}_{5} \mathrm{COOC}_{6} \mathrm{H}_{5}+\left(\mathrm{C}_{6} \mathrm{H}_{5} \mathrm{O}\right)_{2} \mathrm{POH}
$$

In order to simplify the phosphorylation reaction, 2-chloro-1, 3, 2-dioxaphosphorane was reacted with a twice molar quantity of imidazole in benzene. After filtering the imidazole salt, benzene was evaporated and a greasy residue of $\mathrm{mp}$ about $35^{\circ} \mathrm{C}$ was isolated as 2-(1-imidazolyl)1, 3, 2-dioxaphosphorane (IOP). ${ }^{5}$

Found: C, 38.59\%; H, 4.72\%; N, 17.50\%. Calcd: $\quad$ C, 37.98\%; H, 4.46\%; N, $17.72 \%$.

$$
\begin{aligned}
& \mathrm{CH}_{2}-\mathrm{O}_{\backslash} \\
& \mathrm{CH}_{2}-\mathrm{O}^{\prime}
\end{aligned}
$$

IOP was reacted with an equal molar quantity of $n$-butylamine or propionic acid in dioxane and an amidation reaction was then carried out by subsequently adding propionic acid or $n$ butylamine, respectively. The reaction rates were determined by measuring the amount of residual amine or carboxylic acid and also the $\mathrm{N}$-butyl propionamide formed by gas chromatography.

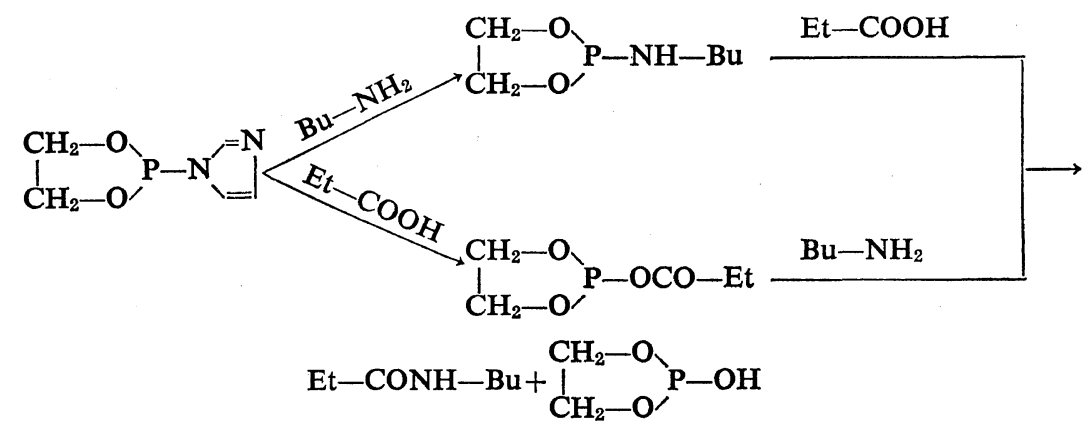


The Reaction Mechanism of Polyamide Synthesis by Phosphorylation

\section{Polycondensation Reaction}

The polycondensation reaction of hexamethylenediammonium adipate (nylon 66 salt) was carried out in DMF at $30^{\circ} \mathrm{C}$ in the presence of various triaryl phosphites and tertiary amines. Nylon salts were suspended at a concentration of $0.5 \mathrm{~mol} / l$ in DMF which contained 3 times of the molar quantity of aryl phosphites and tertiary amines to nylon salts and the suspension was kept at $30^{\circ} \mathrm{C}$ with vigorous stirring. After a given time, a highly swollen gel was formed which was poured into acetone and resulting polyamide was collected by filtration, followed by repeated washing with water and acetone and drying.

A 0.005 -mol portion of adipic acid was dissolved in $10 \mathrm{~m} l$ of DMF which contained 0.015 mol each of triphenyl phosphite and imidazole. The solution was stirred at room temperature. After one hour, a white precipitate was formed and the whole solution became a gel where a large amount of precipitate was obtained after $24 \mathrm{hr}$. The precipitate was identified as adipyl diimidazolide.

Equal moles of adipyl diimidazolide and hexamethylenediamine were mixed with stirring at a concentration of $0.25 \mathrm{~mol} / l$ in $\mathrm{DMF}$ and the solution was kept at 30 or $60^{\circ} \mathrm{C}$ for a given period. The solution transformed into a highly swollen gel which was poured into acetone to isolate the polyamide formed. The polymer was collected by filtration, followed by washing with hot acetone and drying.

The polycondensation of nylon 66 salt by phosphorylation with triphenyl phosphite and imidazole was carried out in DMF in the presence of various metal compounds including metal acetyl acetonates so that the catalytic effect of the metal on the polycondensation was elucidated. Various nylon salts from dicarboxylic acids and hexamethylenediamine were also subjected to the polycondensation by phosphory- lation in a similar method to that of nylon 66 salt.

\section{Polymer Characterization}

Solution viscosities of polyamides were measured in $96-\%$ sulfuric acid at $30^{\circ} \mathrm{C}$ and end group titrations of the resulting polyamide were carried out for both amine and carboxylic groups according to a conventional method. ${ }^{6}$ The amount of phosphorous atom combined with the polyamide was determined by colorimetric analysis of the phosphorous atom. ${ }^{7}$

\section{RESULTS AND DISCUSSION}

\section{Amidation Reaction by Phosphorylation}

The reaction of propionic acid with $n$-butylamine or $n$-hexylamine in the presence of various aryl phosphites and imidazole was carried out in THF at $30^{\circ} \mathrm{C}$ and results are summarized in Figure 1.

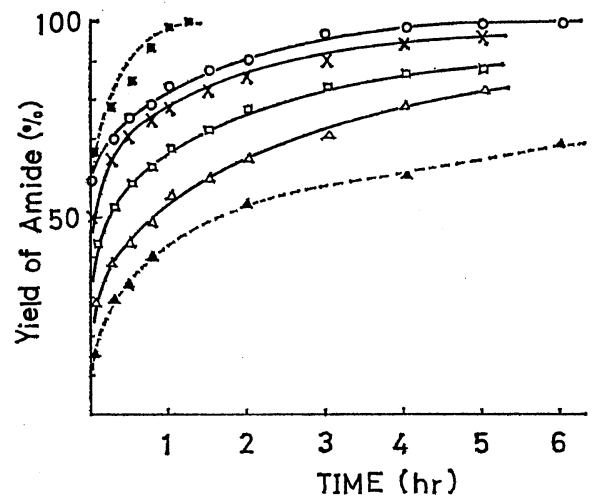

Figure 1. Rates of the amidation reaction of propionic acid with $n$-butylamine or $n$-hexylamine with various triary phosphites and imidazole:

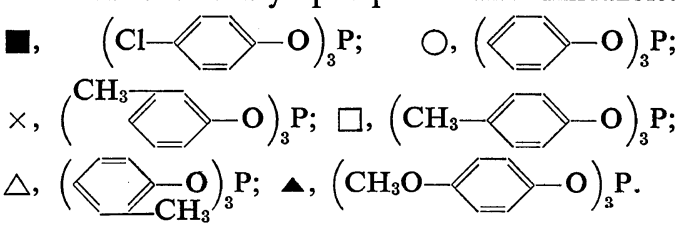

$$
\begin{aligned}
& \mathrm{C}_{2} \mathrm{H}_{5} \mathrm{COOH}+\mathrm{R}-\mathrm{NH}_{2} \frac{\left(\mathrm{R}^{\prime}-\langle=\mathrm{O})_{3} \mathrm{P}\right.}{\mathrm{HN}_{=}^{\prime=\mathrm{N}}} \mathrm{C}_{2} \mathrm{H}_{5} \mathrm{CONH}-\mathrm{R} \\
& \text { R: }-\mathrm{C}_{4} \mathrm{H}_{9} \text { or }-\mathrm{C}_{6} \mathrm{H}_{13}
\end{aligned}
$$




\section{N. Ogata and H. Tanaka}

As can be seen in Figure 1, the rates of the amidation reaction decreased with increasing electron-donating character of the $p$-substituted phenols of aryl phosphites. This result suggests that the cleavage of the $\mathrm{P}-\mathrm{O}$ linkage is the rate-determining step for the amidation reaction since an electron-donating group on the phenyl ring enhances the bond strength of the $\mathrm{P}-\mathrm{O}$ linkage.

Carboxylic acid was found to undergo an

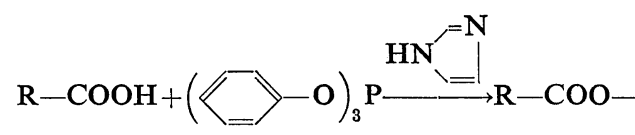

The rates of formation of phenyl propionate were therefore determined by reacting propionic acid with triphenyl phosphite and imidazole at various molar ratios in benzene at $30^{\circ} \mathrm{C}$. Figure 2 indicates that phenyl propionate was formed gradually within one day at $30^{\circ} \mathrm{C}$ when equal moles of triphenyl phosphite and imidazole to propionic acid were used and decrease in the amount of triphenyl phosphite and imidazole retarded the formation rate of phenyl propionate.

It was found that the formation of phenyl ester by phosphorylation requires a time unit of days, while the amidation of carboxylic acid by phosphorylation was completed within a few hours. Figure 3 indicates rates of the formation of $N$-hexyl propionamide either by the phosphorylation of propionic acid and $n$-hexylamine, or by the reaction of phenyl propionate with

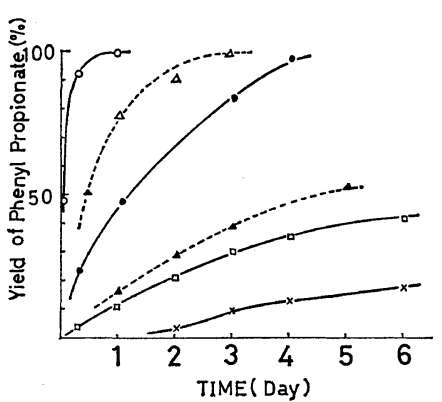

Figure 2. Rates of formation of phenyl propionate from propionic acid by triphenyl phosphite and imidazole. Ratios of propionic acid/triphenyl phosphite/imidazole: $O, 1 / 1 / 1 ; \triangle, 3 / 2 / 1 ; \bullet, 2 / 1 / 1$; $\triangle, 3 / 1 / 1 ; \square, 4 / 1 / 1 ; \times, 10 / 1 / 1$. Monomer concentration, $0.3 \mathrm{~mol} / l$ in benzene at $30^{\circ} \mathrm{C}$. esterification reaction in the presence of triphenyl phosphite and imidazole to form a phenyl ester. Since phenyl ester is known to be an active ester ${ }^{8}$ which easily reacts with amine to form amide at room temperature, the amidation reaction by the phosphorylation with triaryl phosphite and imidazole might pass through the formation of phenyl ester as a reaction intermediate which might be subsequently subjected to the amidation reaction.

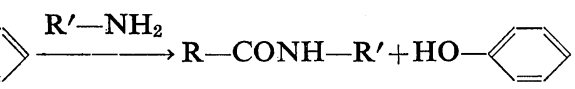

$n$-hexylamine. It is seen in Figure 3 that the amidation reaction by phosphorylation took place with a faster rate than the reaction of phenyl propionate. Since the rate of phenyl esterification and the amidation reaction of phenyl ester with amine were found to be much slower than the rate of the amidation reaction by phosphorylation, the reaction path passing through the formation of phenyl ester as a main intermediate to form amide could be ignored although the formation of phenyl ester cannot be completely denied. Therefore, the amidation reaction must pass through a phosphorous-containing intermediate which is formed from aryl phosphite with amine or carboxylic acid.

Another plausible route for the amidation reaction could be postulated where carboxylic acid may react with imidazole to form acyl

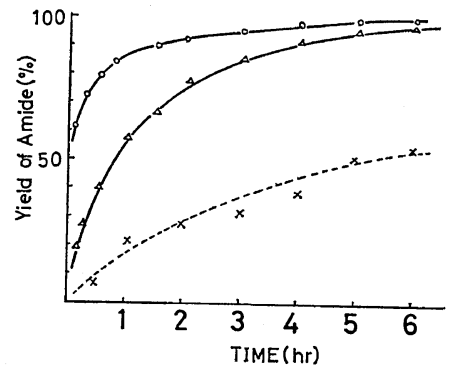

Figure 3. Rates of formation of $N$-hexyl propionamide by phosphorylation or from phenyl proponate: $\bigcirc$, phosphorylation with triphenyl phosphite; $\triangle$, phenyl propionate and $n$-hexylamine; -----, rate of the formation of phenyl propionate from triphenyl phosphite and imidazole. Monomer concentration, $0.5 \mathrm{~mol} / l$ in $\mathrm{THF}$ at $30^{\circ} \mathrm{C}$. 
imidazolide in the presence of triphenyl phosphite and the imidazolide formed may subsequently react with amine to form amide as follows.

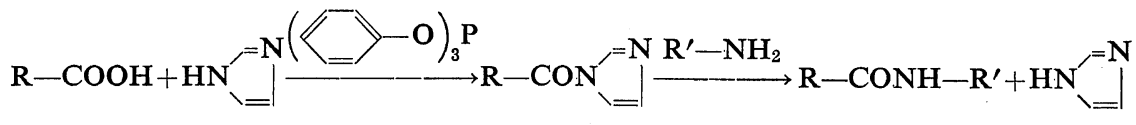

When propionic acid was subjected to the reaction with equal moles of triphenyl phosphite and imidazole in DMF, only phenyl propionate was isolated as a main product as described before, and $N$-propyl imidazolide was not detected. However, when adipic acid was reacted with 3 times molar quantity of both triphenyl phosphite and imidazole in DMF at room temperature, a white precipitate was formed, which was identified as adipyl diimidazolide from elementary and infrared analyses as follows.

Found: C, 58.3\%; H, 5.2\%; N, 22.7\%;

Calcd: C, 58.5\%; H, 5.7\%; N, 22.8\%; $\mathrm{mp}, 187^{\circ} \mathrm{C}$.

The yield of adipyl diimidazolide reached as high as $90 \%$ within $5 \mathrm{hr}$ as shown in Table I. Therefore, when diimidazolide is separated out of the solution owing to a low solubility, the reaction route passing through the formation of

Table I. Yields of adipyl diimidazolide from adipic acid by the phosphorylation ${ }^{a}$

\begin{tabular}{cc}
\hline Time, hr & Yield, $\%$ \\
\hline 0.5 & 24 \\
1 & 48 \\
3 & 85 \\
5 & 87 \\
24 & 90 \\
\hline
\end{tabular}

a Adipic acid $0.5 \mathrm{~mol} / \mathrm{l}$, triphenyl phosphite 1.5 $\mathrm{mol} / l$, imidazole $1.5 \mathrm{~mol} / l$, solvent $\mathrm{DMF}$, room temperature. diimidazolide cannot be ignored.

In order to simplify the reaction mechanism, 2-chloro-1, 3, 2-dioxaphosphorane (CDP) was reacted with propionic acid or $n$-butylamine in dioxane in the presence of triethylamine at $30^{\circ} \mathrm{C}$, and the solutions were subsequently reacted with $n$-butylamine or propionic acid, respectively. The rates of formation of $N$-butyl propionamide by two different orders of addition are compared in Figure 4 where it is seen that the rate of the amidation reaction is almost the same whether by first reacting CDP with amine or carboxylic acid, followed by subsequent reactions of carboxylic acid or amine with resulting phosphorous compounds, as shown in following equations.

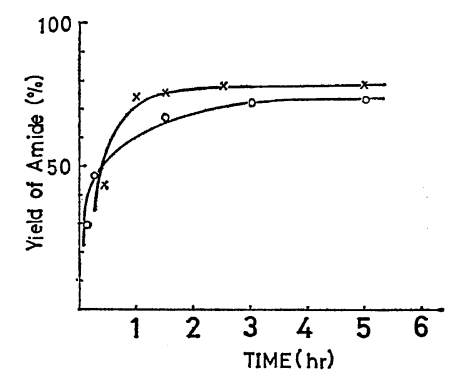

Figure 4. Rates of formation of $N$-butyl propionamide by reacting CDP with propionic acid or $n$-butylamine, followed by subsequent addition of $n$-butylamine or propionic acid, respectively: $x, \mathrm{CDP}+\mathrm{C}_{2} \mathrm{H}_{5} \mathrm{COOH}$ and then $+n-\mathrm{BuNH}_{2} ; \mathrm{O}$, $\mathrm{CDP}+n-\mathrm{BuNH}_{2}$ and then $+\mathrm{C}_{2} \mathrm{H}_{5} \mathrm{COOH}$. Monomer concentration, $0.5 \mathrm{~mol} / l$ in $\mathrm{THF}$ at $30^{\circ} \mathrm{C}$.

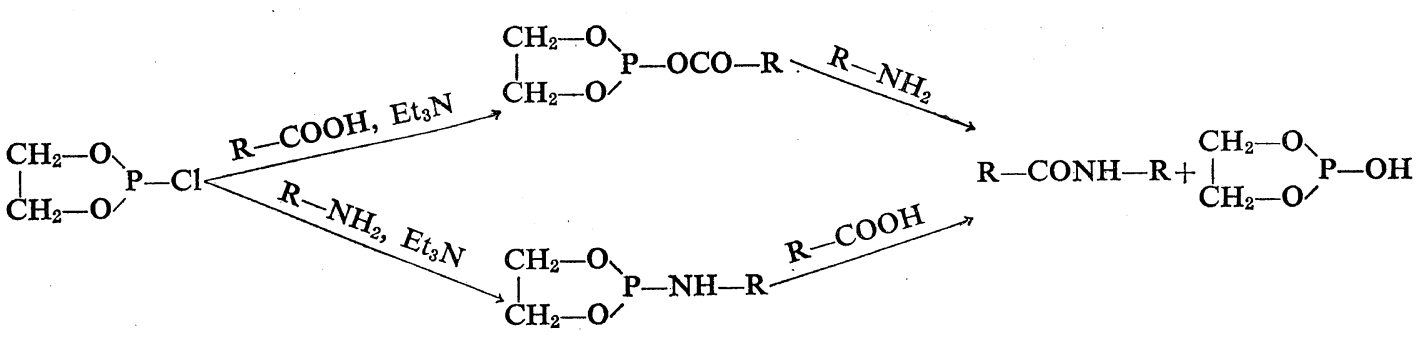


Therefore, the reactivity of phosphoramide toward carboxylic acid is presumed to be approximately the same as that of acyloxy phosphite toward amine. On the other hand, the exchange reaction of phosphoramide and acyloxy phosphite did not occur to form amide, since it was confirmed that no amide was formed by mixing phosphoramide with acyloxy phosphite.

2-(1-Imidazolyl)-1, 3, 2-dioxaphosphorane (IOP) was reacted with propionic acid or $n$-butylamine in dioxane at $30^{\circ} \mathrm{C}$ and rates of the consumption of propionic acid or $n$-butylamine were measured as shown in Figure 5 which indicates that the reaction of IOP with carboxylic acid or amine was completed within one hour as soon as they were mixed together and very little free propionic acid or $n$-butylamine remained in the solution. When equal moles of $n$-butylamine or propionic acid were added to this solution (which was presumed to contain amine or carboxylic acid complexes with IOP), a very rapid formation of $N$-butyl propionamide was observed either by reacting these complexs with propionic acid or $n$-butylamine, respectively. These results are indicated in Figure 5 and reactions are shown in following equations.
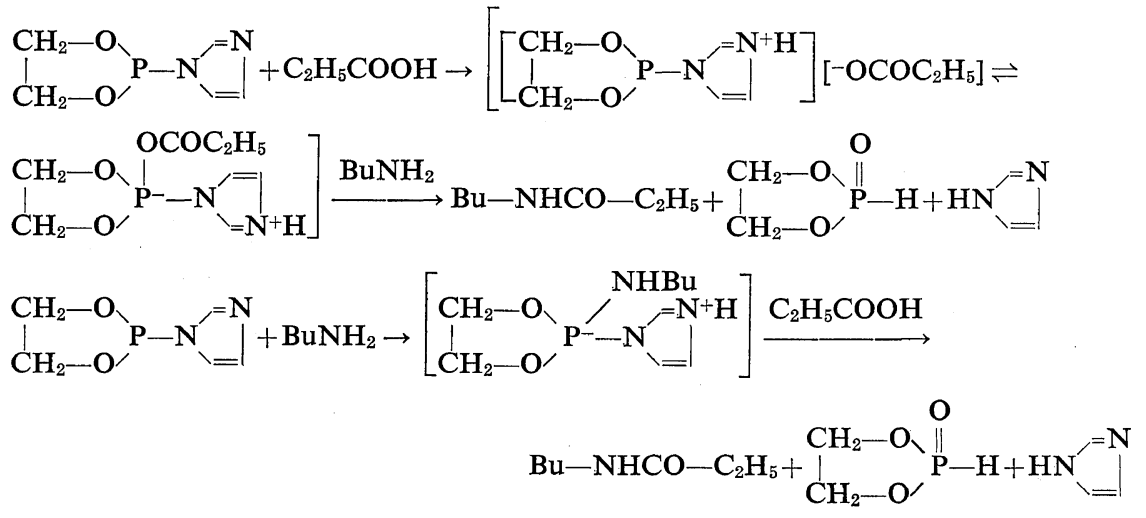

The rate of the amidation reaction from these IOP complexes was almost instantaneously rapid and was much faster than that from acyloxy

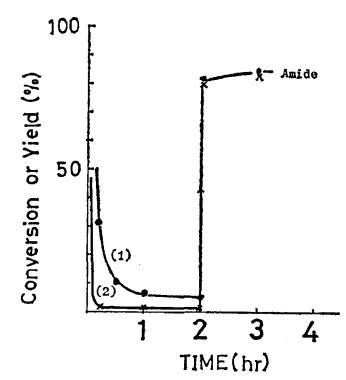

Figure 5. Rates of reaction of IOP with propionic acid or $n$-butylamine and the amidation reaction of the IOP complex with $n$-butylamine or propionic acid: (1), reaction of IOP with propionic acid (2), reaction of IOP with $n$-butylamine; after $2 \mathrm{hr}$ of the reaction, $n$-butylamine or propionic acid were added to the solution. Monomer concentration, $0.5 \mathrm{~mol} / l$ in dioxane. phosphite or phosphoramide as one can see by comparing Figures 4 and 5. Therefore, imidazolyl phosphite was found to be much more reactive toward the amidation reaction than acyloxy phosphite or phosphoramide. This reason might be attributed to a complex formation of imidazolyl phosphite with amine or carboxylic acid, which might enhance the reactivity of amine or carboxylic acid attached on the phosphorus atom to form amide as shown in eq 9 and 10.

\section{Reaction of Triphenyl Phosphite with Imidazole}

When equal moles of triphenyl phosphite and imidazole were mixed in THF at room temperature, no phenol was found in the solution. The solution was evaporated under vacuum and a greasy oil was obtained, which was decomposed by heating at raised temperatures. Elementary analysis of the grease was as follows

C, 65.5\%; H, 5.10\%; N, 7.25\%.

This analytical result was consistent with 
The Reaction Mechanism of Polyamide Synthesis by Phosphorylation

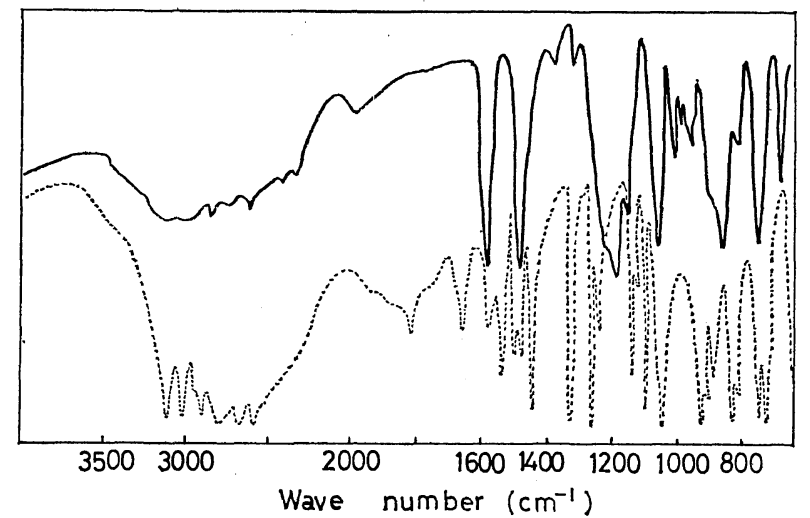

Figure 6. Infrared spectrum of the reaction product of triphenyl phosphite and imidazole: —-, reaction product; -.---., imidazole.

calculated values of a simple mixture of triphenyl phosphite and imidazole as $\mathrm{C}, 66.7 \% ; \mathrm{H}, 5.03 \%$; $\mathrm{N}, 7.41 \%$.

The infrared spectrum of the grease is shown in Figure 6 where it is seen that absorptions owing to the $\mathrm{N}-\mathrm{H}$ group of imidazole at around $3000 \mathrm{~cm}^{-1}$ disappeared and absorptions owing to $-\mathrm{C}=\mathrm{C}-$ and $-\mathrm{C}=\mathrm{N}-$ groups were shifted toward lower frequencies. Strong absorptions owing to $-\mathrm{P}-\mathrm{O}-\mathrm{C}$ appeared at 1200 and $1070 \mathrm{~cm}^{-1}$.

The NMR spectrum of the grease is shown in
Figure 7. It is seen in Figure 7 that chemical shifts of the protons of the reaction product from triphenyl phosphite and imidazole were simple overlaps of those of triphenyl phosphite and imidazole just after the mixing. However, after $24 \mathrm{hr}$ of mixing several new signals were appeared at 8.5 and around $6.9 \mathrm{ppm}$. Chemical shifts at around $6.9 \mathrm{ppm}$ could be asigned to phenyl protons of phenoxide group. From these results the reaction product of triphenyl phosphite and imidazole might have the following structure

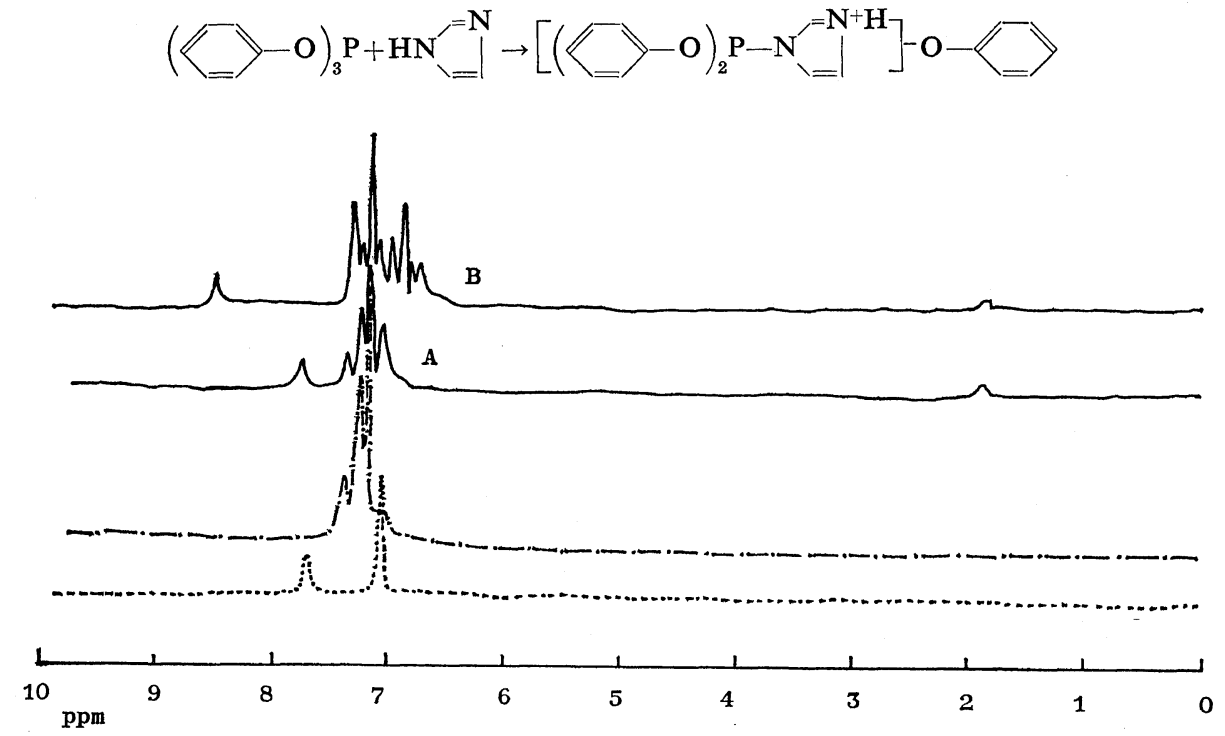

Figure 7. NMR spectrum of the reaction product of triphenyl phosphite and imidazole: -----, imidazole; -.---, triphenyl phosphite; A, imidazole+triphenyl phosphite, B, after $24 \mathrm{hr}$. 


\section{Polycondensation Reaction}

The polycondensation reaction of nylon 66 salt was carried out in DMF in the presence of various triaryl phosphite and imidazole at $30^{\circ} \mathrm{C}$

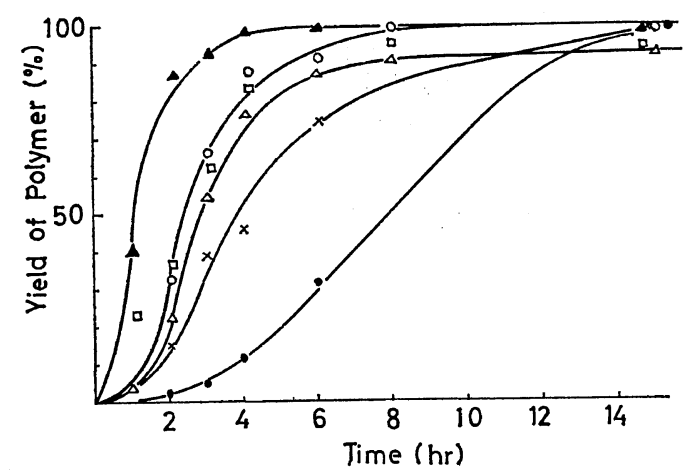

Figure 8. Rates of the polycondensation of nylon 66 salt by phosphorylation with various triaryl phosphites and imidazole: $\Delta,(\mathrm{Cl}-\mathrm{O})_{3} \mathrm{P}$;

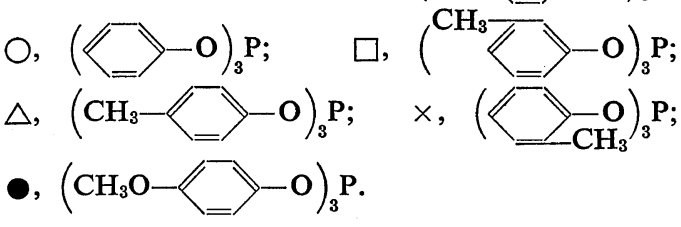

Table II. Polycondensation of nylon 66 salt with triaryl phosphites and imidazole at $30^{\circ} \mathrm{Ca}$

\begin{tabular}{|c|c|c|c|}
\hline \multirow{2}{*}{ Triaryl phosphite } & \multirow{2}{*}{$\underset{\mathrm{hr}}{\text { Time, }}$} & \multicolumn{2}{|c|}{ Polymer } \\
\hline & & $\begin{array}{c}\text { Yield, } \\
\%\end{array}$ & $\eta_{\text {inh }}$ \\
\hline & $\begin{array}{r}8 \\
14\end{array}$ & $\begin{array}{r}100 \\
98\end{array}$ & $\begin{array}{l}0.14 \\
0.16\end{array}$ \\
\hline & $\begin{array}{r}6 \\
14\end{array}$ & $\begin{array}{l}75 \\
94\end{array}$ & $\begin{array}{l}0.12 \\
0.16\end{array}$ \\
\hline & $\begin{array}{r}8 \\
14\end{array}$ & $\begin{array}{l}96 \\
97\end{array}$ & $\begin{array}{l}0.17 \\
0.16\end{array}$ \\
\hline$(-0)_{3}$ & $\begin{array}{r}8 \\
14\end{array}$ & $\begin{array}{l}91 \\
93\end{array}$ & $\begin{array}{l}0.15 \\
0.16\end{array}$ \\
\hline & $\begin{array}{r}6 \\
14\end{array}$ & $\begin{array}{r}99 \\
100\end{array}$ & $\begin{array}{l}0.11 \\
0.10\end{array}$ \\
\hline$-v_{-0}$ & $\begin{array}{r}6 \\
14\end{array}$ & $\begin{array}{r}31 \\
100\end{array}$ & $\begin{array}{l}0.11 \\
0.10\end{array}$ \\
\hline
\end{tabular}

a Polycondensation was carried out in a monomer concentration of $0.5 \mathrm{~mol} / l$ in $\mathrm{DMF}$ at $30^{\circ} \mathrm{C}$.

$\mathrm{b}$ Amount of triary phosphite and imidazole were $3 \mathrm{~mol}$ to $1 \mathrm{~mol}$ of nylon salt.
Table III. Effect of tertiary amines on the polycondensation of nylon 66 salt by phosphorylation $^{2}$

\begin{tabular}{lcrc}
\hline & & \multicolumn{2}{c}{ Polymer } \\
\cline { 3 - 4 } Tertiary amine $^{\mathrm{b}}$ & $\begin{array}{c}\text { Time, } \\
\mathrm{hr}\end{array}$ & $\begin{array}{c}\text { Yield, } \\
\%\end{array}$ & $\eta_{\text {inh }}$ \\
\hline Imidazole & 43 & 100 & 0.19 \\
2-Methylimidazole & 44 & 93 & 0.19 \\
2-Phenylimidazole & 44 & 55 & 0.13 \\
Pyridine & 44 & 33 & - \\
1, 2, 3-Benzotriazole & 48 & 34 & - \\
Rhodanine & 48 & 26 & - \\
Pyrrole & 24 & 14 & - \\
$\gamma$-Picoline & 24 & 7 & - \\
Triethylamine & 44 & 4 & - \\
Morpholine & 65 & 0 & - \\
\hline
\end{tabular}

a Polycondensation of nylon 66 salt was carried out in a monomer concentration of $0.5 \mathrm{~mol} / l$ in DMF at $30^{\circ} \mathrm{C}$ in the presence of $3 \mathrm{~mol}$ of triphenyl phosphite to $1 \mathrm{~mol}$ of nylon salt.

b Amount of amines was $3 \mathrm{~mol}$ to $1 \mathrm{~mol}$ of nylon salt.

and the results are summarized in Figure 8 and Table II. As indicated in Figure 8 , the rates of polycondensation decreased with increasing electron-donating character of substituted phenols of triaryl phosphite and this effect of triaryl phosphite on the polycondensation was consistent with results of the amidation reaction of model compounds as previously mentioned. Polycondensation of nylon 66 salt with triphenyl phosphite and various tertiary amines was carried out and the results are summarized in Table III where it is seen that only imidazole had a very strong effect in forming polyamide and substitution on imidazole nucleous with alkyl or phenyl groups decreased the yield of polyamide.

Polycondensation of nylon 66 salt was carried out by phosphorylation with triphenyl phosphite and imidazole in the presence of a catalytic amount of various metal compounds. Results are indicated in Table IV, which shows that the addition of copper, magnesium or nickel acetylacetonates increased solution viscosities of the resulting polyamide although the yield of polyamide decreased. On the other hand, equimolar addition of metal acetylacetonates inhibited the polycondensation. 
The Reaction Mechanism of Polyamide Synthesis by Phosphorylation

Table IV. Polycondensation of nylon 66 salt by phosphorylation in the presence of metal compoundsa

\begin{tabular}{lccccc}
\hline \multicolumn{2}{c}{ Metal compounds } & & \multicolumn{2}{c}{ Polymer } \\
\cline { 1 - 2 } Kind & $\begin{array}{c}\text { Amount, } \\
\text { mol\% } \%\end{array}$ & & Time & $\begin{array}{c}\text { Yield, } \\
\%\end{array}$ & $\eta_{\text {inh }}$ \\
\hline None & - & 14 & 98 & 0.16 \\
$\mathrm{Cu}(\mathrm{AcAc})_{2}{ }^{\mathrm{b}}$ & 4 & 42 & 86 & 0.25 \\
$\mathrm{Ni}(\mathrm{AcAc})_{2}$ & 4 & 24 & 86 & 0.23 \\
$\mathrm{Mg}(\mathrm{AcAc})_{2}$ & 4 & 42 & 89 & 0.22 \\
$\mathrm{Co}(\mathrm{AcAc})_{2}$ & 4 & 42 & 97 & 0.16 \\
$\mathrm{Zr}(\mathrm{AcAc})_{4}$ & 4 & 24 & 100 & 0.15 \\
$\mathrm{MgCl}{ }_{2}$ & 4 & 24 & 95 & 0.22 \\
$\mathrm{CuCl}$ & 4 & 24 & 95 & 0.20 \\
$\mathrm{Cu}(\mathrm{OAc})_{2}{ }^{\mathrm{c}}$ & 4 & 24 & 91 & 0.16 \\
$\mathrm{Fe}(\mathrm{AcAc})_{2}$ & 100 & 48 & 0 & - \\
$\mathrm{Cu}(\mathrm{AcAc})_{2}$ & 100 & 48 & 0 & -
\end{tabular}

a Polycondensation was carried out in a monomer concentration of $0.5 \mathrm{~mol} / l$ in $\mathrm{DMF}$ at $30^{\circ} \mathrm{C}$. The amount of triphenyl phosphite and imidazole was $3 \mathrm{~mol}$ per $1 \mathrm{~mol}$ of nylon salt.

b AcAc means acetyacetonate.

c OAc means acetate.
Polycondensation of various dicarboxylic acids with hexamethylenediamine was carried out in DMF in the presence of triphenyl phosphite and imidazole at $30^{\circ} \mathrm{C}$ and the results are summarized in Table V. It is seen in Table $\mathrm{V}$ that polycondensation rates decreased with increasing acid strength of the dicarboxylic acid and no polyamide was formed from malonic acid. Since malonic acid has an active hydrogen, it is presumed that a reaction of the active hydrogen with the phosphite-imidazole complex might occur, resulting in the inhibition of the polycondensation. Active dicarboxylic acid having hetero atoms such as oxygen or sulfur, which had a high reactivity ${ }^{9}$ in the polycondensation with diamine did not show any peculiar behavior in the phosphorylation.

\section{Reaction Mechanism}

The mechanism of the amidation reaction by the phosphorylation with triaryl phosphite and imidazole is postulated as shown below. ${ }^{10,11}$

Table V. Polycondensation of various dicarboxylic acids with hexamethylenediamine by phosphorylation ${ }^{2}$

\begin{tabular}{|c|c|c|c|c|c|c|c|}
\hline \multicolumn{3}{|c|}{ Dicarboxylic acid } & \multicolumn{4}{|c|}{ Polymer yield, \% } & \multirow{2}{*}{$\begin{array}{c}\eta_{\text {inh }} \text { after } \\
4 \mathrm{hr}\end{array}$} \\
\hline Kind & $\mathrm{p} K_{1}$ & $\mathrm{p} K_{2}$ & $1 \mathrm{hr}$ & $2 \mathrm{hr}$ & $3 \mathrm{hr}$ & $4 \mathrm{hr}$ & \\
\hline $\mathrm{HOOCCOOH}$ & 6.28 & 4.27 & 8 & 23 & 25 & 38 & 0.08 \\
\hline $\mathrm{HOOCCH}_{2} \mathrm{COOH}$ & 2.69 & 5.70 & 0 & 0 & 0 & 0 & - \\
\hline $\mathrm{HOOC}\left(\mathrm{CH}_{2}\right)_{2} \mathrm{COOH}$ & 4.21 & 5.64 & 59 & 80 & 91 & 93 & 0.12 \\
\hline $\mathrm{HOOC}\left(\mathrm{CH}_{2}\right)_{4} \mathrm{COOH}$ & 4.42 & 5.41 & 8 & 32 & 71 & 90 & 0.20 \\
\hline $\mathrm{HOOC}\left(\mathrm{CH}_{2}\right)_{8} \mathrm{COOH}$ & 4.60 & 5.60 & 57 & 93 & 97 & 99 & 0.14 \\
\hline $\mathrm{HOOCCH}_{2} \mathrm{OCH}_{2} \mathrm{COOH}$ & - & - & 21 & 48 & 60 & 60 & 0.19 \\
\hline $\mathrm{HOOCCH}_{2} \mathrm{SCH}_{2} \mathrm{COOH}$ & - & - & 58 & 80 & 84 & 86 & 0.22 \\
\hline $\mathrm{HOOCCH}{ }_{2} \mathrm{CH}_{2} \mathrm{SCH}_{2} \mathrm{CH}_{2} \mathrm{COOH}$ & - & - & 68 & 86 & 98 & 99 & 0.18 \\
\hline
\end{tabular}

a Polycondensation was carried out in a monomer concentration of $0.5 \mathrm{~mol} / \mathrm{l}$ in DMF and the amount of triphenyl phosphite and imidazole was $3 \mathrm{~mol}$ per $1 \mathrm{~mol}$ of nylon salt.

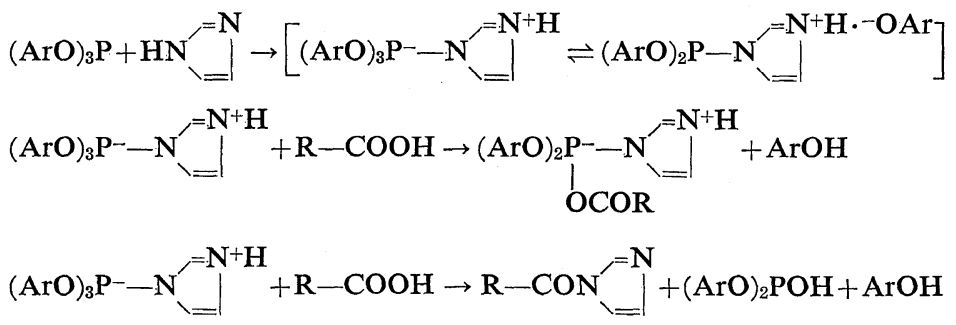




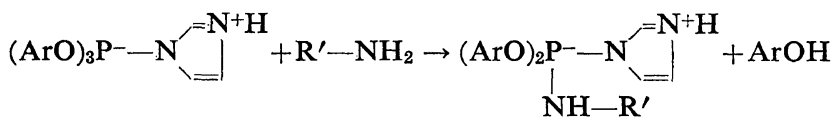

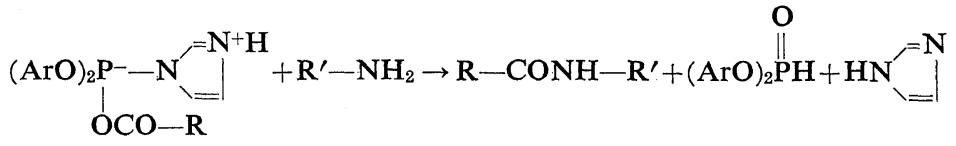

$$
\begin{aligned}
& \underset{\mathrm{NH}-\mathrm{R}^{\prime}}{(\mathrm{ArO})_{2} \mathrm{P}^{-}-\mathrm{N}^{\prime}=\mathrm{N}^{++} \mathrm{H}}+\mathrm{R}-\mathrm{COOH} \rightarrow \mathrm{R}-\mathrm{CONH}-\mathrm{R}^{\prime}+(\mathrm{ArO})_{2} \mathrm{PH}+\mathrm{HN}_{\backslash}^{\prime=} \\
& \mathrm{R}-\mathrm{CON}^{\prime}=\mid+\mathrm{R}^{\prime}-\mathrm{NH}_{2} \rightarrow \mathrm{R}-\mathrm{CONH}-\mathrm{R}^{\prime}+\mathrm{HN}_{\backslash=}^{\prime=}
\end{aligned}
$$

Since a trialkyl phosphite such as triethyl phosphite did not cause the polycondensation of nylon salt, the complex formation of imidazolyl phosphite with carboxylic acid or amine with elimination of phenol is presumed to be the rate-determining step of the subsequent amidation reaction. This presumption could be verified from the amidation reaction with various substituted phenyl phosphites and imidazole as previously mentioned that electron-donating substituents on phenyl retarded the amidation reaction. Alkyl phosphite may not have enough reactivity to form a complex with imidazole and amine or carboxylic acid owing to the strong inductive effect of the alkyl group.

Substitution on imidazole nucleus with alkyl or phenyl groups also decreased the catalytic activity of the imidazolyl phosphite. The inductive effect of alkyl or phenyl groups on the imidazole might weaken the complex formation with triphenyl phosphite, thus leading to poor catalytic activity on phosphorylation.

It was previously found ${ }^{2}$ that the amount of triphenyl phosphite should be more than one mole per mole of nylon salt, while the amount of imidazole could be reduced to a catalytic amount such as 0.08 mole per mole of nylon salt. As postulated in eq 16 and 17, the imidazole combined with the imidazolyl phosphite complex is again liberated by the reaction with amine or carboxylic acid and the reproduced imidazole might again form the imidazolyl phosphite complex. Therefore, the amount of imidazole could be reduced to a catalytic amount. On the other hand, triphenyl phosphite transformed into diphenyl phosphonate which might not form a complex with imidazole having enough reactivity to form amide. Thus, the amount of triphenyl phosphite has to be stoichiometric to the amount of nylon salt.

As previously reported, ${ }^{2}$ the yield of polyamide by the phosphorylation of nylon salt was almost quantitative, while the molecular weight of the resulting polyamide was not satisfactory. Some termination reactions must therefore occur to stop the growth of polymer chains during polycondensation. As previously mentioned in the model reaction, the phosphorylation of carboxylic acid or amine by the imidazolyl phosphite complex occurred at almost the same rate. However, since dicarboxylic acids or amines have different dissociations of two functional groups, the rates of the phosphorylation reaction of dicarboxylic acid or diamines might differ from each other and a kind of competitive reactions of the imidazolyl phosphite complex with dicarboxylic acid and diamine might take place. It is assumed that a predominant formation of the diamine-phosphite complex as described in eq 15 might take place so that dicarboxylic acid might react with this complex to form polyamide with free carboxylic group at the end of polymer chains.

This assumption could be verified from the end group titration of the polyamide formed. After the polycondensation of nylon 66 salt was completed in DMF in the presence of triphenyl phosphite and imidazole, the solution was poured into hot benzene and the resulting polyamide was collected. The end group determination of 
The Reaction Mechanism of Polyamide Synthesis by Phosphorylation

Table VI. Molecular weight of polyamide calculated by end groupa

\begin{tabular}{|c|c|c|c|c|c|c|}
\hline \multirow{2}{*}{ Method of washing } & \multicolumn{2}{|c|}{ Polymer } & \multirow{2}{*}{ P content, } & \multicolumn{3}{|c|}{ Molecular weight } \\
\hline & $\underset{\%}{\text { Yield, }}$ & $\eta_{\text {inh }}$ & & $-\mathrm{NH}_{2}$ & $\mathbf{P}$ & $-\mathrm{COOH}$ \\
\hline Hot benzene & 117 & 0.22 & 3.35 & 2220 & 1910 & 920 \\
\hline Hot benzene & 111 & 0.19 & 2.94 & 2150 & 2170 & 780 \\
\hline $10-\% \mathrm{HCl}$ & 61 & 0.22 & 0.09 & 2300 & - & 1850 \\
\hline $10-\% \mathrm{NaOH}$ & 81 & 0.19 & 0.19 & 2200 & - & 1800 \\
\hline Boiling water & 93 & 0.19 & 1.21 & 2810 & 2650 & 1710 \\
\hline
\end{tabular}

a Polycondensation was carried out in a monomer concentration of $0.5 \mathrm{~mol} / \mathrm{l}$ in DMF at $30^{\circ} \mathrm{C}$ in the presence of $3 \mathrm{~mol}$ of triphenyl phosphite and imidazole per $1 \mathrm{~mol}$ of nylon salt.

the polyamide was carried out according to a conventional method ${ }^{6}$ and the amount of phosphorus atom in the polyamide was determined by a colorimetric method.

Molecular weights calculated from the amine end group are summarized in Table VI which indicates that they are almost twice as much as those calculated from carboxylic end groups, and the calculated molecular weight from phosphorus contents in the polyamide is almost consistent with the molecular weight calculated from the amine end groups when it is postulated that the phosphorus atom is combined at the end of the polymer chains. When the polyamide obtained was treated with $10-\%$ aqueous solution of hydrogen chloride or sodium hydroxide, or with hot water, the phosphorus content in the polyamide decreased as indicated in Table VI. Therefore, it appears to be clear that the phosphorus atom was combined with the polyamide at the end since solution viscosities of the polyamide did not change by these treatments.

From these results, the end groups structure of the polyamide might be rich in phosphoramide group at the one end and carboxyl or acyloxy phosphite groups attached at the other end, as follows.

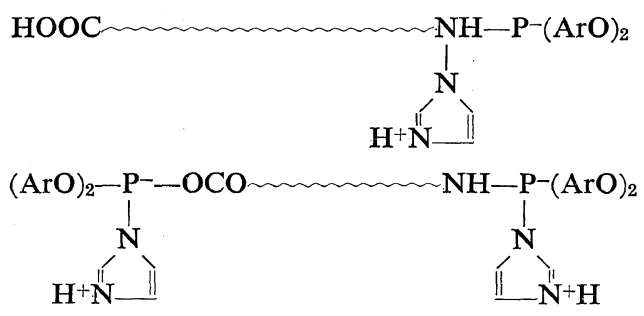

Since an exchange reaction between the phosphoramide and the acyloxy phosphite did not occur, the molecular weight might not increase after the phosphorylation reaction is completed, owing to the molar balance loss of functional groups and also to the phosphorylation of all end groups.

When the polycondensation of nylon salt was completed by means of phosphoylation with triphenyl phosphite and imidazole, a few moles of adipic acid or hexamethylenediamine were added to the solution in an atempt to increase the molecular weight so that the added adipic acid or hexamethylenediamine might react with phosphorylated end groups to extend polymer chains. As shown in Table VII, solution viscosities of the resulting polyamide slightly

Table VII. Effect of post-polycondensation ${ }^{a}$

\begin{tabular}{cccccc}
\hline \multicolumn{2}{c}{ Post addition of monomer } & & \multicolumn{2}{c}{ Polymer } \\
\cline { 1 - 2 } \cline { 5 - 6 } $\begin{array}{c}\text { Adipic acid, } \\
\text { mol\% } \%\end{array}$ & $\begin{array}{c}\text { Hexamethylenedi- } \\
\text { amine, mol } \%\end{array}$ & & $\begin{array}{c}\text { Yield, } \\
\%\end{array}$ & $\eta_{\text {inh }}$ \\
\hline 0 & 0 & & 98 & 0.19 \\
5 & 0 & & 95 & 0.20 \\
10 & 0 & & 98 & 0.21 \\
15 & 0 & & 99 & 0.22 \\
0 & 5 & & 100 & 0.19 \\
0 & 10 & & 97 & 0.22 \\
0 & 15 & 99 & 0.23 \\
\hline
\end{tabular}

a Polycondensation was carried out in a monomer concentration of $5 \mathrm{~mol} / l \mathrm{in} \mathrm{DMF}$ at $30^{\circ} \mathrm{C}$ for $24 \mathrm{hr}$ in the presence of $3 \mathrm{~mol}$ of triphenyl phosphite and imidazole per $1 \mathrm{~mol}$ of nylon salt. Postpolycondensation was carried out by adding adipic acid or hexamethylenediamine to the solution at $30^{\circ} \mathrm{C}$ for another $5 \mathrm{hr}$. 


\section{N. Ggata and H. Tanaka}

increased due to the addition of diamine or dicarboxylic acid as a chain extender, indicating that a post-polycondensation occurred. Therefore, the molar balance loss of end functional groups owing to different phosphorylation rates of carboxyl and amine groups might be one of the reasons for the termination reaction. Other reasons for the termination reaction could be postulated as an oxidation of end phosphoryl groups of growing polymer chains. However, no effect of oxygen on the molecular weight of resulting polyamide was observed. The main reason for the termination of polymer growth may therefore, be attributed to many competitive reactions occurred simultaneously as described in eq 12 to 18 .

If the polycondensation is simplified by isolating a single reaction intermediate, the growth of polymer chains may continue. As previously mentioned, diimidazolide could be isolated in an almost quantitative yield by reacting adipic acid with triphenyl phosphite and imidazole in DMF. Adipyl diimidazolide which was isolated by simply filtering the reaction solution of adipic acid, triphenyl phosphite and imidazole, was suspended at a concentration of $0.25 \mathrm{~mol} / l$ in DMF and an equal molar quantity of hexamethylenediamine was added with stirring. The solution was gradually transformed into a swollen gel within $24 \mathrm{hr}$. The gel solution was poured into acetone and polyamide having an inherent viscosity of 1.42 was obtained in $87-\%$ yield. Therefore, if the polycondensation by this phosphorylation method proceeds through a simple reaction route, a polyamide of very high molecular weight is attainable in such mild conditions as room temperature.

As stated in the polycondensation result, certain metal compounds had a cocatalytic effect on the phosphorylation reaction so as to increase the molecular weight of the resulting polyamide. This metal effect might be ascribed to an interaction of the imidazolyl phosphite complex with the metal. For the purpose of obtaining a high-molecular-weight polyamide by phosphorylation, an exclusive formation of the phosphite complex either with diamine or dicarboxylic acid must occur so that the growth of polymer chains is kept outside the limit imposed by the molar balance loss of end functional groups during the polycondensation. This control in the complex formation could be attained by the chelating effect of metal compounds in the reaction system and investigations on this hypothesis are in progress.

\section{REFERENCES}

1. N. Ogata and H. Tanaka, Polymer J., 2, 672 (1971).

2. N. Ogata and H. Tanaka, ibid., 3, 365 (1972).

3. N. Ogata, H. Tanaka, and G. Suzuki, J. Polym. Sci., Polym. Chem. Ed., 11, 675 (1973).

4. O. Mitsunobu, Yuki Gosei Kagaku Kyokaishi (J. Synth. Org. Chem.), 28, 206 (1970).

5. G. W. Anderson, A. C. MacGregor, and R.W. Young, J. Org. Chem., 23, 1236 (1958).

6. J. E. Waltz and G. B. Taylor, Anal. Chem., 19, 448 (1947).

7. N. Ogata and H. Tanaka, Kobunshi Kagaku (Chem. High Polymers), 27, 929 (1970).

8. N. Ogata, K. Sanui, and K. Iijima, J. Polym. Sci., Polym. Chem. Ed., 11, 1095 (1973).

9. N. Ogata, K. Sanui, and K. Okouchi, Polymer J., 5, 186 (1973).

10. Yu. V. Mitin, Tetrahedron Lett., 1969, 5267.

11. Yu. V. Mitin and O. V. Glinskaya, Akad. Nauk USSR, General Chem., 41, 1151 (1971). 